\title{
Mass psychogenic illness: comparison on selected variables between cases and non-cases
}

\author{
Abdullah Al Mamun, ${ }^{1}$ Mohammad Muntasir Maruf, ${ }^{2}$ Avra Das Bhowmik, ${ }^{3}$ Khaleda Begum, ${ }^{4}$ Zulfiquer Ahmed Amin ${ }^{5}$ \\ ${ }^{1}$ Professor, Department of Psychiatry, Dhaka Medical College, Dhaka, Bangladesh; ${ }^{2}$ Assistant Professor, Department of \\ Psychiatry, Shaheed M. Monsur Ali Medical College, Sirajganj, Bangladesh; ${ }^{3}$ Associate Professor, Department of Psychiatry, \\ Shaheed Ziaur Rahman Medical College, Bogra, Bangladesh; ${ }^{4}$ Associate Professor, Department of Psychiatry, Dhaka Medical \\ College, Dhaka, Bangladesh; ${ }^{5}$ Officers' Trainer, Armed Forces Medical Institute, Dhaka, Bangladesh.
}

$\begin{array}{ll}\text { Article info } & \\ \text { Received } & : \text { 03 July } 2017 \\ \text { Accepted } & : \text { 19 Feb. } 2018 \\ \text { Number of tables } & : 10 \\ \text { Number of figures } & : 0 \\ \text { Number of refs } & : 18\end{array}$

Correspondence: Mohammad Muntasir Maruf Mobile: +8801711339516

E-mail: marufdmc@gmail.com

\begin{abstract}
Summary
Mass psychogenic illness is not new in Bangladesh but in the year 2007, the sudden outbreak all over Bangladesh created a panic nationwide. The objective of the study was to investigate sociodemographic and other variables attributed to the disease. The first outbreak of this illness took place in Adiabad Islamia High School and College, Raipura, Narsinghdi. We rationally decided to conduct our research in this school in case-control design. Within 12 months' study period, 125 students of class VI to X ( 45 cases and 80 controls) were interviewed face-to-face by structured questionnaire containing separate questionnaire for students and guardians. The result of the study showed that, all the cases came from lower socioeconomic class, majority $(71.1 \%)$ from 14 to 16 years age group and most $(77.8 \%)$ of the cases were female. Outbreak rapidly spread among the cases mostly by smelling foul odor ( $40 \%)$ and seeing index cases (33.3\%). Majority (51.2\%) of the cases and controls thought that the illness was due to both physical and psychological causes though most of them (93.6\%) did not hear about the disease previously. It was evident that the role of socio-demographic variables for attributing the symptoms pattern of the disease was ambiguous. However early recognition of psychological stressors and prompt exclusion of physical illness can prevent the occurrence and rapid spread of the disease.
\end{abstract}

Bang J Psychiatry 2016;30(1):14-19

\section{Introduction}

Mass psychogenic illness (MSI) may be defined as a constellation of somatic symptoms suggestive of organic illness, but without an identifiable organic cause that affects the members of a cohesive group rapidly. This phenomenon is also known as multiple synonymous terms which includes mass hysteria, epidemic hysteria, mass panic, collective hysteria and mass sociogenic illness. It has been described for more then 600 years in a variety of cultures and settings but is seldom addressed during medical training. ${ }^{1}$ In the standard psychiatric nomenclature, mass psychogenic illness is subsumed under the general heading of "somatoform disorder", subcategorized as "conversion disorder" or "hysterical neurosis, conversion types". 2 In such episodes, psychological distress is converted or channeled into physical symptoms. In 1987, Simon Wessely has concluded that mass hysteria may be divided into two syndromes. One form, to be called "mass anxiety hysteria", consists of episode of acute anxiety, occurring mainly in school children. In this form, prior tension is absent and rapid spread is by visual contact. Treatment consists of separating the participants and the prognosis is good. The second form, to be called "mass motor hysteria", consists of abnormalities in motor behavior. It occurs in any age group and prior tension is present. Initial cases can be identified and the spread is gradual. Treatment should be directed towards the underlying stressors but the outbreak may be prolonged. ${ }^{3}$

Outbreaks of mass psychogenic illness have been documented in numerous cultural, ${ }^{4}$ ethnic ${ }^{5}$ and religious ${ }^{6}$ groups throughout the world. They have been attributed to the work of evil spirits or the spirits of dead ancestors and intervention by traditional or ritual healers is not uncommon. ${ }^{4-}$ ${ }^{6}$ In Western cultures, demons and possessed states have been replaced largely by toxic chemicals and environmental pollutions as purported causes of epidemic hysteria. ${ }^{7}$ Many factors contribute to the formation and spread of hysterical illness: the mass media; rumors; extraordinary anxiety or excitement; cultural beliefs and stereotypes; the social and political context; and reinforcing actions by authorities such as politicians, or institutions of social control such as the police or the military. Episodes are also distinguishable by the redefinition of mundane objects, events, and circumstances 
and reflect a rapidly spreading folk belief, which contributes to an emerging definition of the situation. ${ }^{8}$

In 1974, Francois Sirois published an historical survey of outbreaks of what he termed 'epidemic hysteria' that had occurred between 1872 and $1972 .{ }^{6}$ In 1997 Leslie P. Boss reviewed outbreaks of epidemic hysteria reported in the English language literature as having occurred from 1973 through 1993 (period 2) and compared and contrasted these reports with those from the period $1872-1972$ (period 1). ${ }^{9}$ Bartholomew RE (2000) described St. Vitus Dance or Dancing Mania between the $11^{\text {th }}$ and $17^{\text {th }}$ centuries swept across Europe among tens of thousands of people, participated in frenzied orgies and wild dances lasting for days and sometimes weeks. Women howled and made obscene gestures while others squealed like animals. ${ }^{10}$

An outbreak of mass psychogenic illness took place in all over Bangladesh in the month of July 2007; on $11^{\text {th }}$ July, 2007 few students of Adiabad Islamia High School and College of Narsingdi district became sick. Within few days, the illness spread out in different places of Bangladesh involving about 18 districts. In this background the objective of the study was to investigate socio-demographic and other variables attributed to the disease.

\section{Materials and methods}

This case-control study was carried out from September 2007 to August 2008 in Adiabad Islamia High School and College, Raipura, Narsinghdi, Bangladesh, situated in a rural area about $80 \mathrm{~km}$ away from the capital Dhaka, on the bank of the river Arialkha where the first outbreak of this illness took place. Students from class VI to $\mathrm{X}$ of the institute were the study population. The record preserved by Adiabad Islamia High School and College authority showed that 50 students of the institute were diagnosed as cases of mass psychogenic illness in different hospitals (DMCH, Narsinghdi district hospital and Raipura Upazilla Health Complex) and by medical team in campus. At the beginning of the study this 50 students were included as 'case' and double (100) number of students were selected as 'control'. Controls were selected from non-affected students of same age, sex \& classes from the same school through systemic sampling technique. From the case group, three students who were transferred from the school and two Secondary School Certificate (SSC) examinees did not attend the interview. From the selected 100 healthy controls, twelve SSC examinees and eight students of other classes did not attend the interview. So, final sample size was 45 cases and 80 controls (total 125). After obtaining formal permission from concerned authority, research team formally communicated with identified cases of mass psychogenic illness and their parents. Matched controls and their guardians were informed in the same manners. After written informed consent from them, research team collected relevant data pertinent to the research by structured questionnaire containing separate questionnaire for students and guardians. Data were recorded in database system using spread sheet, and then analyzed by using computer software program Statistical Package for Social Sciences (SPSS) version 14 for windows.

\section{Results}

The study place, Adiabad Islamia High School and College was the index institute among the affected schools in the Raipura Upazilla of Narsingdi District. During the outbreak, total students were 1054 from class VI to XII but total 50 students were affected by the study illness and we were able to interview 45 of them. In the study place, among 1054 students, $60 \%$ were girls and remaining $40 \%$ were boys. Among the affected 45 cases, $77.8 \%$ (35) were girls and remaining $22.2 \%(10)$ were boys. So the attack rate for girls was higher than that for boys $(77.8 \%$ vs. $22.2 \%)$, respectively. In accordance, corresponding control group was taken containing $68.8 \%$ (55) girls and $31.2 \%$ (25) boys from respective classes (Table 1$)$. In the affected group, there was a higher proportion $(73.3 \%)$ of families with monthly income less than taka 3000 , whereas in controls, $41.2 \%$ belonged to this income group family (Table 2).

Table 1: Sex of the respondents $(n=125)$

\begin{tabular}{lccc}
\hline Sex & $\begin{array}{c}\text { Case } \\
\text { Frequency (\%) }\end{array}$ & $\begin{array}{c}\text { Control } \\
\text { Frequency (\%) }\end{array}$ & $\begin{array}{c}\text { Total } \\
\text { Frequency (\%) }\end{array}$ \\
\hline Male & $10(22.2)$ & $25(31.2)$ & $35(28.0)$ \\
Female & $35(77.8)$ & $55(68.8)$ & $90(72.0)$ \\
\hline
\end{tabular}

Table 2: Monthly family income of the respondents $(n=125)$

\begin{tabular}{lccc}
\hline $\begin{array}{l}\text { Monthly income } \\
\text { (in BDT) }\end{array}$ & $\begin{array}{c}\text { Case } \\
\text { Frequency (\%) }\end{array}$ & $\begin{array}{c}\text { Control } \\
\text { Frequency (\%) }\end{array}$ & $\begin{array}{c}\text { Total } \\
\text { Frequency (\%) }\end{array}$ \\
\hline$<3000$ & $33(73.3)$ & $33(41.2)$ & $66(52.8)$ \\
$3000-4999$ & $5(11.1)$ & $24(30.0)$ & $29(23.2)$ \\
$5000-7999$ & $4(8.9)$ & $7(8.8)$ & $11(8.8)$ \\
$8000-9999$ & $0(0)$ & $1(1.3)$ & $1(0.8)$ \\
$10000-14999$ & $0(0)$ & $12(15.0)$ & $12(9.6)$ \\
15000 and above & $3(6.7)$ & $3(3.7)$ & $6(4.8)$ \\
\hline
\end{tabular}

Regarding the occupation of the student's father of case group, $40 \%$ were farmer and $33.3 \%$ businessman. Among controls, the picture was a bit different $(31.3 \%$ farmer and $36.3 \%$ businessman), but not statistically significant, The age 
of the students affected and controls ranged from 11 through 16 , with a mode of 14 for cases and 15 for controls. There seemed to be no relation between attacks and academic performance or examination or persuasion by teacher in the school. In cases and controls, majority were in moderate academic performance group, (73\% and $66 \%$ respectively), followed by good performance group $(22.2 \%$ and $17.5 \%)$ (Table 3). Of the case group, $15.6 \%$ and of controls group, $3.8 \%$ had examination prior to outbreak (Table 4 ). Regarding the vegetative function or behavior, both cases and controls had no significant relation between outbreak and food habit before going to school or sleep pattern of previous night; but $11.3 \%$ of female cases and $1.8 \%$ of female controls was on menstruation during attack. Majority (cases- $91.1 \%$, controls$87.5 \%$ ) of the students had slept well at night before the outbreak. Maximum students had taken breakfast before coming school on the day of outbreak (Table 5). Both cases and controls responded through questionnaire to express perception about existence of ghost or causes of the current illness or nature of the illness. Results showed that $15.6 \%$ cases and $11.2 \%$ controls believed in the existence of ghost but none of cases and only one of controls thought that the illness was due to influence of ghost, whereas among cases and controls, $40 \%$ and $37.5 \%$ respectively believed the presence of smell before the illness as causative factor. By observing the sick students, $33.3 \%$ cases were affected whereas $47.5 \%$ controls thought that the outbreak was due to observing the sick students. Most of the cases and controls, $64.4 \%$ and $43.7 \%$ respectively, believed the illness as both physical and mental in origin. In contrast, $13.3 \%$ cases and $25 \%$ controls thought that the outbreak had only mental causes; $15.6 \%$ cases and $23.7 \%$ controls perceived the illness as physical one (Table 6, Table 7, Table 8).

Six students $(13.3 \%)$ of case group had history of previous episode of same type of illness but all the students of control group were free from previous attack of same type of illness (Table 9). Regarding the prevailing emotional state prior to the illness, $57.8 \%$ cases and $76.2 \%$ control were in normal status, whereas $20 \%$ and $15 \%$ respectively could not remember the emotional status during the outbreak. In contrast, $13.3 \%$ and $8.9 \%$ cases were emotionally depressed and anxious respectively; in case of control $6.3 \%$ and $2.5 \%$ were depressed and anxious respectively (Table 10).

Table 3: Academic performance of the respondents $(n=125)$

\begin{tabular}{lccc}
\hline Academic performance & $\begin{array}{c}\text { Case } \\
\text { Frequency (\%) }\end{array}$ & $\begin{array}{c}\text { Control } \\
\text { Frequency (\%) }\end{array}$ & $\begin{array}{c}\text { Total } \\
\text { Frequency (\%) }\end{array}$ \\
\hline Good & $10(22.2)$ & $14(17.5)$ & $24(19.2)$ \\
Moderate & $33(73.3)$ & $53(66.3)$ & $86(68.8)$ \\
Bad & $2(4.5)$ & $13(16.2)$ & $13(12)$ \\
\hline Total & $45(100)$ & $80(100)$ & $125(100)$ \\
\hline
\end{tabular}

Table 4: Examination prior to outbreak $(n=125)$

\begin{tabular}{lcc}
\hline Examination & Case & Control \\
& Frequency (\%) & Frequency (\%) \\
\hline Yes & $7(15.6)$ & $3(3.8)$ \\
No & $38(84.4)$ & $73(91.2)$ \\
Can't remember & $0(0)$ & $4(5.0)$ \\
\hline
\end{tabular}

Table 5: Behavioral and biological aspects prior to outbreak $(n=125)$

\begin{tabular}{|c|c|c|c|c|c|c|}
\hline \multirow[t]{2}{*}{ Factors } & \multicolumn{3}{|c|}{$\begin{array}{c}\text { Case } \\
\text { Frequency (\%) }\end{array}$} & \multirow{2}{*}{$\begin{array}{c}\text { Control } \\
\text { Frequency (\%) } \\
\text { Yes }\end{array}$} & \multirow[b]{2}{*}{ No } & \multirow[b]{2}{*}{ Can't remember } \\
\hline & Yes & No & Can't remember & & & \\
\hline Sound sleep & $41(91.1)$ & $3(6.7)$ & $1(2.2)$ & $70(87.4)$ & $5(6.3)$ & $5(6.3)$ \\
\hline Food intake before coming school & $44(97.8)$ & $1(2.2)$ & $0(0)$ & $74(92.5)$ & $2(2.5)$ & $4(5.0)$ \\
\hline Menstruation (only female) & $4(11.4)$ & $26(74.3)$ & $5(14.3)$ & $1(1.8)$ & $37(67.3)$ & $17(30.9)$ \\
\hline
\end{tabular}


Table 6: Belief in existence of ghost $(n=125)$

\begin{tabular}{lccc}
\hline Belief & $\begin{array}{c}\text { Case } \\
\text { Frequency (\%) }\end{array}$ & $\begin{array}{c}\text { Control } \\
\text { Frequency (\%) }\end{array}$ & $\begin{array}{c}\text { Total } \\
\text { Frequency (\%) }\end{array}$ \\
\hline Believe & $7(15.6)$ & $9(11.2)$ & $16(12.8)$ \\
Don't believe & $38(84.4)$ & $71(88.8)$ & $109(87.2)$ \\
\hline
\end{tabular}

Table 7: Perception of the main cause of the illness $(n=125)$

\begin{tabular}{lccc}
\hline Assumed cause & $\begin{array}{c}\text { Case } \\
\text { Frequency (\%) }\end{array}$ & $\begin{array}{c}\text { Control } \\
\text { Frequency (\%) }\end{array}$ & $\begin{array}{c}\text { Total } \\
\text { Frequency (\%) }\end{array}$ \\
\hline Ghost & $0(0)$ & $1(1.3)$ & $1(0.8)$ \\
Observing others & $15(33.3)$ & $38(47.5)$ & $53(42.4)$ \\
Experiencing smell & $18(40.0)$ & $30(37.5)$ & $48(38.4)$ \\
Hearing sound & $3(6.7)$ & $0(0)$ & $3(2.4)$ \\
Others & $8(17.8)$ & $1(1.3)$ & $9(7.2)$ \\
Did not answer & $1(2.2)$ & $10(12.4)$ & $11(8.8)$ \\
\hline
\end{tabular}

Table 8: Insight about the illness $(n=125)$

\begin{tabular}{lccc}
\hline Insight & $\begin{array}{c}\text { Case } \\
\text { Frequency (\%) }\end{array}$ & $\begin{array}{c}\text { Control } \\
\text { Frequency (\%) }\end{array}$ & $\begin{array}{c}\text { Total } \\
\text { Frequency (\%) }\end{array}$ \\
\hline Physical & $7(15.6)$ & $19(23.7)$ & $26(20.8)$ \\
Mental & $6(13.3)$ & $20(25)$ & $26(20.8)$ \\
Both physical and mental & $29(64.4)$ & $35(43.7)$ & $64(51.2)$ \\
Ghost & $0(0)$ & $1(1.3)$ & $1(0.8)$ \\
Others & $3(6.7)$ & $4(5.0)$ & $7(5.6)$ \\
Did not answer & $0(0)$ & $1(1.3)$ & $1(0.8)$ \\
\hline
\end{tabular}

Table 9: History of previous episode of same illness $(n=125)$

\begin{tabular}{lccc}
\hline History & Case & Control & Total \\
& Frequency (\%) & Frequency (\%) & Frequency (\%) \\
\hline Present & $6(13.3)$ & $0(0)$ & $6(4.8)$ \\
Absent & $39(86.7)$ & $80(100)$ & $119(95.2)$ \\
\hline
\end{tabular}

Table 10: Emotional status prior to the illness $(n=125)$

\begin{tabular}{lccc}
\hline Emotional status & $\begin{array}{c}\text { Case } \\
\text { Frequency (\%) }\end{array}$ & $\begin{array}{c}\text { Control } \\
\text { Frequency (\%) }\end{array}$ & $\begin{array}{c}\text { Total } \\
\text { Frequency (\%) }\end{array}$ \\
\hline Good & $26(57.8)$ & $61(76.2)$ & $87(69.6)$ \\
Depressed & $6(13.3)$ & $5(6.3)$ & $11(8.8)$ \\
Anxious & $4(8.9)$ & $2(2.5)$ & $6(4.8)$ \\
Could not remember & $9(20.0)$ & $12(15.0)$ & $21(16.8)$ \\
\hline
\end{tabular}




\section{Discussion}

There are typically characteristic features of mass hysteria preponderance of illness in preadolescent or adolescents, prevalence in girls or young women, rapid spread with the apparent transmission of illness by sight or sound, presence of hyperventilation and / or syncope, absence of findings or laboratory results confirming an organic cause, evidence of physical and psychological stress, rapid remission of symptoms and relapse of the same illness in the setting of the original outbreak. ${ }^{8}$

Investigators of modern-day outbreaks of mass psychogenic illness in school and job settings have used standardized personality tests to identify social, psychological and other characteristics, in trying to tell why some members of the same group are affected whereas others are not. There is no consistent pattern. Their conflicting and inconclusive findings are not surprising because episodes involve social realities and the consequences of beliefs. Thirty-five affected workers at a fish packaging plant scored higher than controls on the Eysenck Personality Inventory scale for extroversion, ${ }^{11}$ whereas 90 affected electronics assembly workers scored lower than those who were unaffected. Goldberg associated absenteeism and mass sociogenic illness, ${ }^{12}$ but Cole did not. ${ }^{13}$ Gary Small and his colleagues link academic performance and becoming ill, ${ }^{14}$ whereas Goh found no association. ${ }^{15}$ Small also correlated the death of a significant other during early childhood and being stricken with epidemic hysteria, ${ }^{14}$ and yet this observation was not confirmed in another study by the same researcher. ${ }^{16}$

In the present study, although students, teachers, guardians, and the principle of the school were questioned extensively about psychological stressors, such as examinations, holidays, academic performance, illness, food habit, school environment, personal changes and community stress, no predisposing factor could be identified. As the study was started several weeks later the breakdown, any underlying psychological or physical stress might remain hidden during study.

The index case was the female student of class $X$, who had the past history of having the attack of conversion disorder. During this study, she was interviewed and found as having anxiety-prone personality. She was one of the meritorious students of her class, always facing stress from parents to do extraordinary result in SSC examination. Following index, within two weeks, all the cases affected by mass psychogenic illness. During that period, the climate was also so hot that students demanded to avoid assembly.

Most of the cases were female teenagers. Open or hidden impact of gender discrepancy both in family and social level might be one of the causative factors to make them psychologically weak. Being a good student, index case might be the role model of them. But during study it was found that most of the cases and controls believed that the illness was transmitted by experiencing smell, audiovisual cues were the next assumed cause. In the other researches during the $20^{\text {th }}$ century unsubstantiated claims of strange odor and gassings were a common contemporary trigger of MSI outbreaks in schools. ${ }^{13,17,18}$ Other studies also showed that sirens, flashing light and even television cameras or microphones can significantly fuel the hysteria cycle. Other audiovisual cues such as the appearance of police, ambulance and firefighting vehicles in the commons, the movement of large groups of students out of the index building, and the noise of all this activities may have made students feel uneasy and apprehensive. Line of sight and other forms of audiovisual transmission could well have accounted for the spread of illness in the absence of person-to-person contact. ${ }^{16}$

The case-control study was conducted in a selected rural school. So, the study population might not represent the whole community. All the students affected with mass psychogenic illness were included as cases. For controls, systemic sampling technique was applied, though desired number of respondents could not be included. As some of the information was collected with a semi-structured questionnaire based on the memory of the respondents, there remain possible chances of recall bias.

\section{Conclusion}

For developing countries like Bangladesh, the outbreak of mass psychogenic illness is a burden to the health sector and economy. It is evident from the study that the role of socio-demographic variables for attributing the symptoms pattern of this disease is ambiguous. However early recognition of psychological stressors and prompt exclusion of physical illness can prevent the occurrence and rapid spread of the disease. Despite a number of limitations, this study provides base line information about mass psychogenic illness in Bangladesh. The findings need to be addressed carefully and need evaluation extensively before drawing any conclusion.

\section{References}

1. Bartholomew RE, Wessely S. Protean nature of mass sociogenic illness from nuns to chemical and biological terrorism fears. Br J Psychiatry 2002;180:300-6.

2. American Psychiatric Association. Diagnostic and statistical manual of mental disorders. $4^{\text {th }}$ ed. Washington DC: American Psychiatric Association; 1994.

3. Wessely S. Mass hysteria: two syndroms? Psychol med 1987;17(1):109-20. 
4. Sirois F. Perspectives on epidemic hysteria. In: Colligan M, Pennebaker J, Marphy P, editors. Mass psychogenic illness: a social psychological analysis. $3^{\text {rd }}$ ed. Hillsdale (NJ): Lawrence Erlbaum; 1982. p. 217-36.

5. Armstrong H, Patterson P. Seizures in Canadian Indian children: individual, family and community approaches. Can Psychiatr Assoc J 1975;20(4):247-55.

6. Sirois F. Epidemic hysteria. Acta Psychitr Scand Suppl 1974;252:1-46.

7. Franchini A. A manifestation interpreted as collective hysteria presenting as symptoms of intoxication by flammable gas. Medicina di Lavoro 1947;38:57-60.

8. Bartholomew RE, Goode E. Mass delusions and hysterias: Highlights from the past millennium. Skeptical Inquirer 2000;24(3):20-8.

9. Boss LP. Epidemic hysteria: a review of the published literature. Epidemiol Rev 1997;19:233-43.

10. Bartholomew RE. Exotic deviance: medicalizing cultural idioms - from strangeness to illness. Boulder, CO: University Press of Colorado; 2000.
11. Smith M, Colligan M, Hurrell J. Three incidents of industrial mass psychogenic illness. J Occup Med 1978;20:339-400.

12. Goldberg EL. Crowd hysteria in a junior high school. Journal of School Health 1973;43:362-6.

13. Cole TB, Chorba TL, Horan JM. Pattern of transmission of epidemic hysteria in a school. Epidemiology 1990;1(3):212-8.

14. Small GW, Propper MW, Randolph ET, Eth S. Mass hysteria among student performers: social relationship as a symptom predictor. Am J Psychiatry 1991;148(9):1200-5.

15. Goh KT. Epidemiological enquiries into a school outbreak of an unusual illness. Int J Epidemiol 1987;16:265-70.

16. Small GW, Borus JF. Outbreak of illness in a school chorus: Toxic poisoning or mass hysteria? N Engl J Med 1983;308(11):632-5.

17. Small GW, Feinberg DT. Steinberg D, Collins MT. A sudden outbreak of illness suggestive of mass hysteria in school children. Arch Fam Med 1994;3(8):711-6.

18. Selden BS. Adolescent epidemic hysteria presenting as a mass casualty, toxic exposure incident. Ann Emerg Med 1989;18(8):892-5. 